\title{
CRESCIMENTO E DESENVOLVIMENTO DE AVEIA PRETA EM RESPOSTA À INOCULAÇÃO COM Azospirillum brasilense E ADUBAÇÃO NITROGENADA
}

Douglas Vilas Boas Correa Filho, Érika Cristina Souza da Silva Correia, Francisco José Domingues Neto, David Vitor dos Santos, Tiago Alexandre da Silva, Raimundo Nonato Farias Monteiro, Lais Fernanda Fontana

Faculdade de Tecnologia Paulista, Lupércio, SP. Universidade Estadual Paulista "Júlio de Mesquita Filho", UNESP.

\section{RESUMO}

A bactéria Azospirillum brasilense vem ganhando destaque quando inoculadas em sementes, resultando em incrementos no sistema radicular, produção de massa seca e produtividade das culturas. Objetivou-se com esse trabalho comparar os efeitos da inoculação de $A$. brasilense e a aplicação de diferentes doses de adubo nitrogenado sob a produção da aveia preta, buscando minimizar os custos de produção. 0 experimento foi realizado em campo, área experimental pertencente à Faculdade de Tecnologia Paulista, Lupércio-SP. O delineamento experimental foi em blocos casualizados com cinco tratamentos ( $\mathrm{T} 1=$ testemunha, aveia preta não inoculada com $A$. brasilense e sem aplicação de $\mathrm{N} ; \mathrm{T} 2=A$. brasilense na dose de $0,25 \mathrm{~mL} / 14 \mathrm{~g}$ de semente, no momento da semeadura; T3= $\mathrm{N} 50 \%$ na dose de $19 \mathrm{~g} / 2 \mathrm{~m}^{2}, 30$ dias após a germinação; T4= N 100\% na dose de $38 \mathrm{~g} / 2 \mathrm{~m}^{2}$ e T5= N 150\% na dose de $57 \mathrm{~g} / 2 \mathrm{~m}^{2}$, 30 dias após a germinação) e quatro repetições. Aos 90 dias após a semeadura avaliou-se a altura das plantas, massa fresca e seca da parte aérea e das sementes. Houve efeito significativo da aplicação de $A$. brasilense e nitrogênio em plantas de aveia preta para todos os parâmetros avaliados, exceto altura, massa seca da parte aérea e massa fresca da semente. A inoculação de sementes de aveia preta com $A$. brasilense favoreceu a produção, obtendo resultados semelhantes à adubação nitrogenada, portanto seu uso pode ser uma alternativa aos produtores, visando a redução de custos com adubações químicas.

Palavras-chave: Avena strigosa; bactéria diazotrófica; fixação biológica de nitrogênio; componentes de produção

\section{GROWTH AND DEVELOPMENT OF BLACK OATS IN RESPONSE TO INOCULATION WITH Azospirillum brasilense AND NITROGEN FERTILIZATION}

\begin{abstract}
Bacterium Azospirillum brasilense has been gaining prominence when inoculated in seeds, resulting in root system increments, dry mass production and crop productivity. The objective of this work was to compare the effects of inoculation of $A$. brasilense and the application of different doses of nitrogen fertilizer under the production of black oats, in order to minimize production costs. The experiment was carried out at the experimental field belonging to the Faculty of Technology of São Paulo, Lupércio-SP, whose geographical

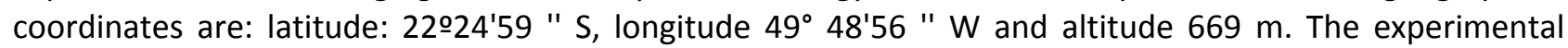
design was randomized blocks with five treatments ( $\mathrm{T} 1=$ control, black oat not inoculated with $A$. brasilense and without application of $\mathrm{N}, \mathrm{T} 2=A$. brasilense at the dose of $0.25 \mathrm{~mL} / 14 \mathrm{~g}$ of seed, at the time of sowuing; $\mathrm{T} 3=\mathrm{N} 50 \%$ at the dose of $19 \mathrm{~g} / 2 \mathrm{~m}^{2}, 30$ days after germination; $\mathrm{T} 4=\mathrm{N} 100 \%$ at the dose of $38 \mathrm{~g} / 2 \mathrm{~m}^{2}$ and $\mathrm{T} 5=\mathrm{N} 150 \%$ at the dose of $57 \mathrm{~g} / 2 \mathrm{~m}^{2}, 30$ days after germination) and four replicates. The sowing was done manually and in lines, being sown 292 seeds per linear meter. At 90 days after sowing the height of the plants was evaluated and then the plants were harvested and evaluated the fresh mass of the aerial part and the seeds and, after drying in an air circulation oven, the dry mass of the aerial part and seeds. There was a significant effect of the application of $A$. brasilense and nitrogen on black oat plants for all evaluated parameters, except for height, dry shoot mass and fresh seed mass. The inoculation of $A$. brasilense on black oat seeds favored the production, obtaining results similar to nitrogen fertilization.
\end{abstract}

Keywords: Avena strigosa; diazotrophic bactéria; biological nitrogen fixation; production componentes. 


\section{INTRODUÇÃO}

A aveia preta (Avena strigosa Schreb.) é uma forrageira anual que apresenta rápido crescimento inicial, com alta produção de matéria fresca no primeiro pastejo, desenvolvimento uniforme, bom perfilhamento, alto valor nutritivo, boa digestibilidade, sendo uma excelente alternativa para ser utilizada na alimentação dos bovinos ou como planta de cobertura durante o período de outono/inverno (SKONIESKI et al., 2011). Sua importância tem crescido expressivamente nos últimos anos, principalmente com a adoção do sistema de plantio direto, tornando-se uma espécie fundamental no esquema de rotação de culturas, sendo adaptada tanto na região temperada quanto subtropical, onde tem destaque na produção de massa seca, não sendo muito exigente em relação a solos; porém, responde bem à adubação nitrogenada, fosfatada e potássica. (SOUZA et al., 2009; DEMÉTRIO et al., 2012).

$O$ nitrogênio $(\mathrm{N})$ é considerado $\mathrm{O}$ nutriente que mais limita a produção de massa seca de gramíneas forrageiras, tendo o seu maior efeito na cultura da aveia. Sua deficiência reduz drasticamente o desenvolvimento das plantas, afetando o número de folhas e perfilhos, se tornando fundamental para manutenção da produtividade e da sustentabilidade da pastagem (MENDEIROS; NABINGER, 2001; VIANA et al., 2011).

Diversos trabalhos têm elucidado os efeitos positivos da adubação nitrogenada na produtividade de gramíneas, destacando resultados encontrados em aveia e azevém (CASSOL et al., 2011); milho (SOUZA et al., 2011; FARINELLI; LEMOS, 2012), aveia branca (MANTAI et al., 2015), trigo (TEIXEIRA FILHO et al., 2010; COSTA et al., 2013; THEAGO et al., 2015), capimmombaça (CANTO et al.,2012); capim-braquiária (MARANHÃO et al., 2010), entre outros.

Devido à grande importância do nitrogênio no desenvolvimento das plantas, estudos têm sido direcionados a fixação biológica de nitrogênio através de bactérias, sendo uma alternativa promissora, pois esses microrganismos atuam na disponibilidade da produção de auxinas, substâncias responsáveis pelo estímulo do crescimento (REIS JÚNIOR et al., 2008). O gênero Azospirillum spp. tem a capacidade de realizar fixação biológica do nitrogênio, colonizando a superfície das raízes, rizosfera, filosfera e tecidos internos das plantas (HUNGRIA et al., 2015).

A bactéria Azospirillum brasilense vem ganhando destaque quando inoculadas em sementes, resultando em incrementos no sistema radicular, na produção de massa seca e na produtividade das culturas (DARTORA et al., 2013; RODRIGUES et al., 2014). Diversos trabalhos comprovam o sucesso da utilização de A. brasilense em gramíneas como aveia, milho, trigo e arroz (NOVAKOWISKI et al., 2011; DIMINGUES NETO et al., 2014; RODRIGUES et al., 2014; GARCIA et al, 2016; MULLER et al., 2016).

O uso de fertilizantes nitrogenados é responsável por elevar os custos na produção agrícola, sendo prática comum na condução das culturas devido o nitrogênio ser considerado um dos nutrientes mais importantes para o funcionamento adequado das plantas. A inoculação de bactérias fixadoras de nitrogênio é uma alternativa de redução de custos na produção, favorecendo benefícios diretos (fixação biológica de nitrogênio, produção de fitormônios (sobretudo auxinas) e solubilização de fosfato inorgânico) e indiretos (indução sistêmica de resistência a doenças, controle biológico e produção de compostos orgânicos que captam ferro (sideróforos)) sobre a planta (DOBBELAERE; OKON, 2007).

Em função do exposto objetivou-se com esse trabalho comparar os efeitos da inoculação de sementes com $A$. brasilense e diferentes doses de adubo nitrogenado sob o crescimento e desenvolvimento da aveia preta, buscando minimizar os custos de produção.

\section{MATERIAL E MÉTODOS}

O experimento foi conduzido no campo experimental pertencente à Faculdade de Tecnologia Paulista, localizada no município de Lupércio-SP, cujas coordenadas geográficas de referência são: latitude: 2224'59" S, longitude $49^{\circ} 48^{\prime} 56^{\prime \prime}$ W e altitude $669 \mathrm{~m}$.

Realizou-se análise química do solo (0-20 $\mathrm{cm}$ ) e pela interpretação dos resultados, não foi necessária a realização de calagem (Tabela 1 ). A adubação de plantio foi realizada segundo recomendações do boletim 100 (RAIJ et al., 1996), consistindo em $60 \mathrm{~kg} / \mathrm{ha}$ de Super Fosfato Simples ( $P-18 \%), 20 \mathrm{~kg} / \mathrm{ha}$ de Cloreto de Potássio ( $\mathrm{KCL}-60 \%$ ) e Sulfato de Amônia ( $\mathrm{N}$ $21 \%)$, sendo a aplicação deste último realizada de três formas diferentes (50, 100 e 150\%). 
Tabela 1. Análise química do solo, campo experimental da Faculdade de Tecnologia Paulista, Lupércio - SP.

\begin{tabular}{cccccccccccc}
\hline $\begin{array}{c}\text { Camada } \\
\mathrm{Cm}\end{array}$ & $\begin{array}{c}\mathrm{pH} \\
\mathrm{CaCl}_{2}\end{array}$ & $\begin{array}{c}\mathrm{M} . \mathrm{O} . \\
\mathrm{g} / \mathrm{dm}^{3}\end{array}$ & $\begin{array}{c}\mathrm{P}_{\text {resina }} \\
\mathrm{mg} / \mathrm{dm}^{3}\end{array}$ & $\begin{array}{c}\mathrm{Al}^{3+} \\
\mathrm{H}+\mathrm{Al}\end{array}$ & $\mathrm{K}$ & $\begin{array}{c}\mathrm{Ca} \\
\mathrm{Mg}\end{array}$ & $\mathrm{SB}$ & $\mathrm{CTC}$ & $\mathrm{V} \%$ \\
\hline $0-20$ & 5,2 & 21 & 8 & 1 & 15 & 2,7 & 12 & 6 & 20,7 & 35,7 & 58 \\
\hline
\end{tabular}

O delineamento experimental utilizado foi em blocos casualizados com cinco tratamentos e quatro repetições, com parcelas de $1 \times 2 \mathrm{~m}\left(2 \mathrm{~m}^{2}\right)$. Os tratamentos foram: T1= testemunha, aveia preta não inoculada com $A$. brasilense e sem aplicação de $\mathrm{N} ; \mathrm{T} 2=A$. brasilense na dose de $0,25 \mathrm{~mL} / 14 \mathrm{~g}$ de semente, no momento da semeadura; $\mathrm{T} 3=\mathrm{N} 50 \%$, na dose de 19 g. $2 \mathrm{~m}^{-2}, 30$ dias após a germinação; T4= N 100 $\%$, na dose de $38 \mathrm{~g} .2 \mathrm{~m}^{-2}$ e T5= N $150 \%$, na dose de $57 \mathrm{~g} .2 \mathrm{~m}^{-2}, 30$ dias após a germinação.

O preparo do solo foi realizado mediante aração e gradagem. A semeadura foi conduzida manualmente e em linhas, no mês de maio sendo semeadas 292 sementes por metro linear. As avaliações da altura $(\mathrm{cm})$, massa fresca e seca da parte aérea $(\mathrm{g})$, massa fresca e seca de semente (g) e massa fresca e seca total da parte aérea e sementes (g) se deram aos 90 dias após a semeadura. Durante a condução do experimento os dados metereológicos (índice pluvial, temperatura e umidade relativa do ar) foram coletados pela Estação Meteorológica de São Carlos (SP), pertencente ao Instituto Nacional de Meteorologia (INMET) (Figura 1).

Figura 1. Índice pluvial, temperatura e umidade relativa do ar durante a condução do experimento nos meses de maio, junho e julho de 2016 em Lupércio, SP (INMET, 2016).
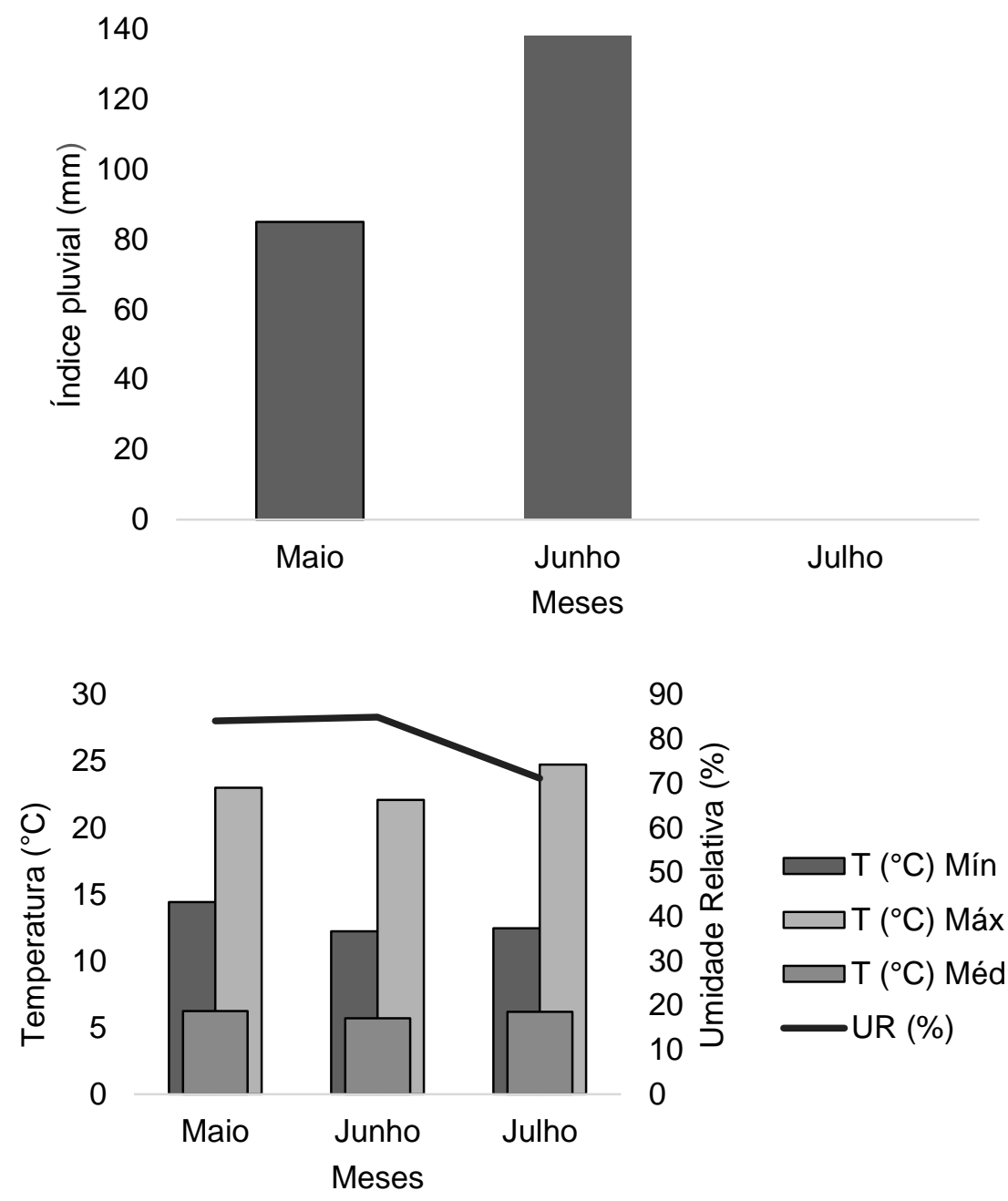
A altura das plantas foi medida em cinco plantas médias por parcela, medindo-se da superfície do solo até o ápice do caule. Após avaliação da altura, as plantas foram cortadas no nível do solo, separadas em parte aérea (folhas+caule) e sementes e avaliadas a massa fresca das plantas e das sementes, para isso, utilizou-se uma balança analítica com precisão de 0,1 g. Para a obtenção da massa seca da parte aérea e sementes, essas foram colocadas para secar em estufa com circulação de ar forçada a 65 oc até atingir massa constante, sendo assim determinada pela pesagem em balança analítica com precisão de $0,1 \mathrm{~g}$. A massa fresca e seca total da parte aérea e sementes foi obtida pela soma das massas frescas e secas.

Os resultados obtidos foram submetidos à análise de variância (Teste F) e as médias comparadas pelo teste Tukey a $5 \%$ de probabilidade. Foi realizada uma análise de correlação entre as variáveis, visando determinar o grau de associação entre elas.

\section{RESULTADOS E DISCUSSÃO}

Não houve diferença estatística para a altura de plantas de aveia preta submetida à inoculação com $A$. brasilense e doses de nitrogênio nos tratamentos avaliados (Tabela 2). Este resultado pode estar relacionado aos fatores ambientais, visto que no período de condução do experimento (maio, junho e julho), a redução da temperatura e do fotoperíodo favoreceram o crescimento das plantas de aveia preta. Estudos anteriores com aveia preta também não verificaram diferença significativa para a altura de plantas pela aplicação de seis doses de nitrogênio (NAKAGAWA et al., 2000).

Tabela 2. Altura (AL), massa fresca e seca da parte aérea (MFPA, MSPA), massa fresca e seca de sementes (MFS, MSS) e massa fresca e seca total (MFT, MST) de plantas de aveia preta tratadas com Azospirillum brasilense e adubação nitrogenada. Lupércio, 2016.

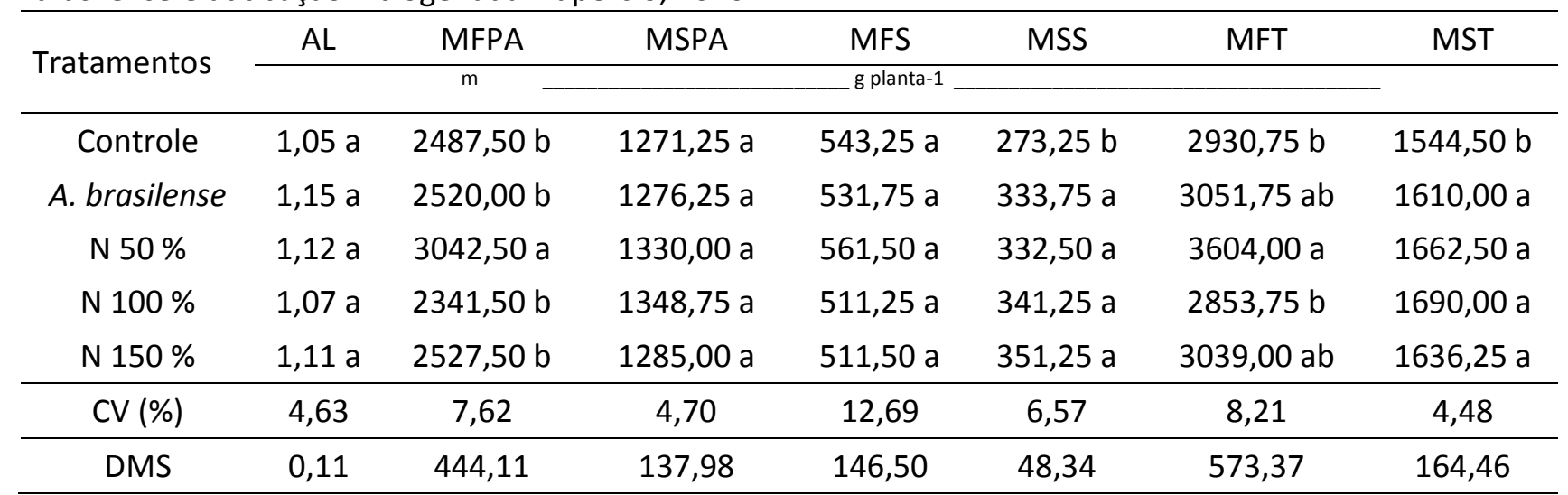

Médias seguidas de mesma letra minúscula na coluna não diferem entre si pelo teste Tukey a $5 \%$ de probabilidade.

A maior massa fresca da parte aérea foi obtida com o tratamento com aplicação de $50 \%$ de nitrogênio, diferindo estatisticamente dos demais. De acordo com os resultados, a maior dose de adubo nitrogenado não favoreceu a maior massa fresca, mesmo sabendo que as gramíneas de maneira geral apresentam grande demanda por N. Segundo Lazenby (1981), as gramíneas de clima temperado $C_{3}$, como é o caso da aveia preta, são menos eficientes no aproveitamento do $\mathrm{N}$ na produção vegetal do que as $\mathrm{C}_{4}$ (cana-de-açúcar, milho, sorgo, braquiárias, milheto).

Não houve diferença significativa entre os tratamentos para a massa seca de planta e massa fresca de sementes. No Paraná, a produção de massa seca de 18 cultivares de aveia preta foi de 590 a $2.476 \mathrm{~kg} \mathrm{ha}^{-1}$, quando aplicado $45 \mathrm{~kg} \mathrm{ha}^{-1}$ de nitrogênio (CECATO et al., 2001). No presente trabalho, a massa seca da parte aérea variou de $1.276,25$ a $1.348,75$ g planta $^{-1}$, demonstrando que esse resultado se encontra dentro dos padrões de produção encontrado por Cecato et al. (2001).

A massa seca das sementes foi influenciada significativamente pelos tratamentos, com valores médios variando entre 333,75 a 351,25 g planta ${ }^{-1}$. Deve-se ressaltar a importância desta variável, visto a relação direta com a produção. Já em sementes de milho, o uso isolado ou associado de $A$. brasilense com doses de nitrogênio não interferiu no desenvolvimento e na produtividade da cultura (REPKE et al., 
2013). O sucesso da associação entre planta e Azospirillum, na maioria das vezes, está relacionado a fatores da própria bactéria, como a escolha da estirpe, o número ideal de células por sementes e sua viabilidade (MEHNAZ; LAZAROVITS, 2006) e também pela espécie da cultura utilizada.

O tratamento N $50 \%$ proporcionou maior benefício quanto a massa fresca, não diferindo dos tratamentos com inoculação de $A$. brasilense e N $150 \%$. Resultados positivos relacionados a inoculação de $A$. brasilense podem ser explicados segundo Radwan et al. (2004) e Dalla Santa et al. (2004) ao maior acúmulo de nitrogênio na planta, maior porcentagem de germinação de grãos e alteração dos diferentes estádios da cultura, obtidos não só em função da maior absorção de água e nutrientes, mas principalmente pela produção de hormônios endógenos de desenvolvimento. Observando os resultados relacionados a massa seca total, todos os tratamentos diferiram estatisticamente do controle, mostrando a eficiência tanto da adubação nitrogenada quanto da inoculação de sementes $\operatorname{com} A$. brasilenses.

Houve correlação positiva significativa entre a maioria das variáveis (Tabela 3). Para a altura de plantas, a correlação foi significativa com a massa fresca da semente $(r=0,629)$ e massa fresca total $(r=0,479)$.

Tabela 3. Correlação entre a altura (AL), massa fresca e seca da parte aérea (MFPA, MSPA), massa fresca e seca de sementes (MFS, MSS) e massa fresca e seca total (MFT, MST) de plantas de aveia preta tratadas com Azospirillum brasilense e adubação nitrogenada, Lupércio, 2016.

\begin{tabular}{lllllll}
\hline & AL & MFPA & MSPA & MFS & MSS & MFT \\
\hline MFPA & $0,388^{\text {NS }}$ & & & & & \\
MSPA & $-0,067^{\text {NS }}$ & $0,472^{*}$ & & & & \\
MFS & $0,629^{* *}$ & $0,614^{* *}$ & $0,538^{*}$ & & & \\
MSS & $0,384^{\text {NS }}$ & $0,350^{\text {NS }}$ & $0,652^{* *}$ & $0,825^{* *}$ & & \\
MFT & $0,479^{*}$ & $0,979^{* *}$ & $0,526^{*}$ & $0,759^{* *}$ & $0,497^{*}$ & \\
MST & $0,126^{\text {NS }}$ & $0,463^{*}$ & $0,941^{* *}$ & $0,717^{* *}$ & $0,868^{* *}$ & $0,564^{* *}$ \\
\hline
\end{tabular}

ns = não significativo; ${ }^{* *} \mathrm{e}^{*}$ significativo a $1 \%$ e $5 \%$ de probabilidade, respectivamente, pelo Teste $\mathrm{t}$.

A massa fresca da parte aérea correlacionou-se com todas as variáveis, exceto com a massa seca da semente. A massa seca da parte aérea, massa fresca e seca das sementes e massa fresca total, correlacionaram-se positivamente com todas as demais variáveis.

\section{CONCLUSÃO}

Os resultados obtidos com o uso de $A$. brasilense e doses de nitrogênio demonstram significativas alterações no crescimento e desenvolvimento de plantas de aveia preta, em função do incremento de massa seca total.

A inoculação de sementes de aveia preta com $A$. brasilense favoreceu a produção, obtendo resultados semelhantes à adubação nitrogenada

\section{REFERÊNCIAS}

CANTO, M.W.; BARTH NETO, A., PANCERA JÚNIOR, E.J.; GASPARINO, E.; BOLETA, V.S. Produção e qualidade de sementes do capimmombaça em função da adubação nitrogenada. Bragantia, v.71, n.3, p.430-437, 2012.

\section{https://doi.org/10.1590/S0006-}

\section{2}

CASSOL, L.C.; PIVA, J.T.; SOARES, A.B.; ASSMANN, B.A.L. Produtividade e composição estrutural de aveia e azevém submetidos a épocas de corte e adubação nitrogenada. Revista Ceres, v.58, p.438-443, 2011. https://doi.org/10.1590/S0034737X2011000400006.

CECATO, O.R.; ALMEIDA, F.C.; GOMES, J.A.N. Produção e composição química em cultivares e linhagens de aveia (Avena spp). Acta Scientiarum, v.23, n.4, p.775-780, 2001.

COSTA, L.; ZUCARELI, C.; RIEDE, C.R. Parcelamento da adubação nitrogenada no desempenho produtivo de genótipos de trigo. Revista Ciência Agronômica, v.44, p.215-224, $2013 . \quad$ https://doi.org/10.1590/S180666902013000200002

DALLA SANTA, O.R.; FERNÁNDEZ, R.; MICHELENA, G.; RONZELLI., P.; SOCCOL, C.R. Azospirillum sp. Inoculation in wheat, barley and oats seeds in 
greenhouse experiments. Brazilian Archives of Biology and Technology, v.47, p.843-849, 2004. https://doi.org/10.1590/S1516-

\section{2}

DARTORA, J.; GUIMARÃES, V.F.; MARINI, D.; SANDER, G. Adubação nitrogenada associada à inoculação com Azospirillum brasilense e Herbaspirillum seropedicae na cultura do milho.

Revista Brasileira de Engenharia Agrícola e Ambiental, v.17, n.10, p.1023-1029, 2013. https://doi.org/10.1590/S1415$\underline{43662013001000001}$

DEMÉTRIO, J.V.; COSTA, A.C.T.; OLIVEIRA, P.S.R. Produção de biomassa de cultivares de aveia sob diferentes manejos de cortes. Pesquisa Tropical Goiânia, v.42, n.2, p.198-205, 2012. https://doi.org/10.1590/S198340632012000200011.

DOBBELAERE, S.; OKON, Y. The plant growthpromoting effect and plant responses. In: ELMERICH, C.; NEWTON, W.E. (eds.). Associative and endophytic nitrogen-fixing bacteria and cyanobacterial associations. Dordrecht, Netherlands: Springer, $2007 . \quad$ p.145-170. https://doi.org/10.1007/1-4020-3546-2 7

DOMINGUES NETO, F.J.; YOSHIMI, F.K.; GARCIA, R.D.; DOMINGUES, M.C.S. Influência de Azospirillum brasilense no desenvolvimento vegetativo, produção de forragem e acúmulo de massa seca da aveia preta. Enciclopédia Biosfera, v.10, n.18; p. 2013-2019, 2014.

FARINELLI, R.; LEMOS, L.B. Nitrogênio em cobertura na cultura do milho em preparo convencional e plantio direto consolidados. Pesquisa Agropecuária Tropical, v.42, p.63-70, 2012.

GARCIA, N.F.S.; A.R.F, O.; PORTUGAL, J.R.; PERES, A.R.; RODRIGUES, M.; PENTEADO, M.S. Doses and application methods of Azospirillum brasilense in irrigated upland rice. Revista Brasileira de Engenharia Agrícola e Ambiental, v.20, n.11, p.990-995, 2016. https://doi.org/10.1590/18071929/agriambi.v20n11p990-995

HUNGRIA, M.; NOGUEIRA, M.A.; ARAÚJO, R.S. Soybean seed co-inoculation with Bradyrhizobium spp. and Azospirillum brasilense: a new biotechnological tool to improve yield and sustainability. American Journal of Plant Science, v.6, n.10, p.811-817, 2015.

https://doi.org/10.4236/ajps.2015.66087.

INMET. Instituto Nacional de Meteorologia. Estações e dados. 2016. Disponível em: <http://www.inmet.gov.br/sim/abre_graficos.ph p>. Acesso em: 05 de out 2016.

LAZENBY, A. Nitrogen relationships in grassland ecosystems. In: INTERNATIONAL GRASSLAND CONGRESS, 14., 1981. Proceedings... Lexington: Westview Press, 1981. p.56-63.

LUZ, P.H.C; HERLING, V.R; BRAGA, G.J.I. Resposta da aveia preta (Avena strigosa Schreb) à irrigação por aspersão e adubação nitrogenada. Acta Scientiarum Agronomy. v.30. n.3, p.421-426, 2008.

https://doi.org/10.4025/actasciagron.v30i3.3555

MANTAI, R.D.; SILVA, J.A.G.; SAUSEN, A.T.Z.R.; COSTA, J.S.P.; FERNANDES, S.B.V.; UBESSI, C. A eficiência na produção de biomassa e grãos de aveia pelo uso do nitrogênio. Revista Brasileira de Engenharia Agrícola e Ambiental, v.19, n.4, p.343-349, 2015. https://doi.org/10.1590/18071929/agriambi.v19n4p343-349

MARANHÃO, C.M.A.; BONOMO, P.; PIRES, A.J.V.; COSTA, A.C.P.R.; MARTINS, G.C.F.; CARDOSO, E.O. Características produtivas do capim-braquiária submetido a intervalos de cortes e adubação nitrogenada durante três estações. Acta Scientiarum. Animal Sciences, v.32, n.4, p.375384, 2010.

MEDEIROS, R.B.; NABINGER, C. Rendimento de sementes e forragem de azevém-anual em resposta a doses de nitrogênio e regimes de corte. Revista Brasileira de Sementes, v.23, p.245-254, 2001. https://doi.org/10.17801/01013122/rbs.v23n2p245-254

MEHNAZ, S.; LAZAROVITS, G. Inoculation effects of Pseudomonasputida. Ghiconacetobacter azotocaptans. and Azospirillum lipoferum on com plant growth iinder greenhouse conditions. Mícrobial Ecology, v.51, n.3, p.326-335, 2006. https://doi.org/10.1007/s00248-006-9039-7

MULLER, T.M.; SANDINI, I.E.; RODRIGUES, J.D.; NOVAKOWISKI, J.K.; BASI, S.; KAMINSKI, T.H. Combination of inoculation methods of Azospirilum brasilense with broadcasting of 
nitrogen fertilizer increases corn yield. Ciência Rural, v.46, n.2, 2016. https://doi.org/10.1590/0103-8478cr20131283

NAKAGAWA, J; CAVARIANI, C; MACHADO, J.R. Adubação nitrogenada no perfilhamento da aveia-preta em duas condições de fertilidade do solo. Pesquisa Agropecuária Brasileira, v.35, n.6, p.1071-1080, 2000.

https://doi.org/10.1590/S0100$\underline{204 \times 2000000600002}$

NOVAKOWISKI, J.H.; SANDINI, I.E.; FALBO, M.K.; MORAES, A.; NOVAKOWISKI, J.H.; CHENG, N.C. Efeito residual da adubação nitrogenada e inoculação de Azospirillum brasilense na cultura do milho. Semina: Ciências Agrárias, v.32, n.4, p.1687-1698, 2011. https://doi.org/10.5433/16790359.2011v32n4Sup1p1687.

RADWAN, T.E.E.; MOHAMED, Z.K.; REIS, V.M. Efeito da inoculação de Azospirillum e Herbaspirillum na produção de compostos indólicos em plântulas de milho e arroz. Pesquisa Agropecuária Brasileira, v.39, n.10, p.987-994, $2004 . \quad$ https://doi.org/10.1590/S0100$\underline{204 \times 2004001000006}$

RAIJ, B., V.; CANTARELLA, H.; QUAGGIO, J. A.; FURLANI, A. M. C. Recomendações de adubação e calagem para o Estado de São Paulo. 2. ed. Campinas: Instituto Agronômico; Fundação IAC, 1996. (Boletim Técnico, 100).

REIS JÚNIOR, F.B.; MACHADO, C.T.T.; MACHADO, A.T.; SODEK, L. Inoculação de Azospirillum amazonense em dois genótipos de milho sob diferentes regimes de nitrogênio. Revista Brasileira de Ciência do Solo, v.32, p. 1139-1146, $2008 . \quad$ https://doi.org/10.1590/5010006832008000300022

REPKE, R. A.; CRUZ, S. J. S.; SILVA, C. J.; FIGUEIREDO, P. G.; BICUDO, S. J. Eficiência da Azospirillum brasilense combinada com doses de nitrogênio no desenvolvimento de plantas de milho. Revista Brasileira de Milho e Sorgo, v. 12, n. 3, p. 214-226, 2013. https://doi.org/10.18512/1980-

6477/rbms.v12n3p214-226.

RODRIGUES, L.F.O.S.; GUIMARÃES, V.F.; SILVA, M.B.; PINTO JUNIOR, A.S.; KLEIN, J.; COSTA, A.C.P.R. Características agronômicas do trigo em função de Azospirillum brasilense, ácidos húmicos e nitrogênio em casa de vegetação. Revista Brasileira de Engenharia Agrícola e Ambiental, v.8, n.1, p.31-37, 2014. https://doi.org/10.1590/S141543662014000100005

SKONIESKI, F.R.; VIÉGAS, J.; BERMUDES, R.F.; NÖRNBERG, J.L.; ZIECH, M.F.; COSTA, O.A.D; MEINERZ, G.R. Composição botânica e estrutural e valor nutricional de pastagens de azevém consorciadas. Revista Brasileira de Zootecnia, v.40, n.3, p.550-556, 2011. https://doi.org/10.1590/S151635982011000300012

SORATTO, R.P.; CARDOSO, S. M.; SILVA, A.H.; COSTA, T.A.M.; PEREIRA, M.; CARVALHO, L.A. Doses e épocas de doses e épocas de aplicação de nitrogênio em cobertura na cultura do painço (Panicum miliaceum L.). Ciência Agrotécnica, v.31, n.6, p.1661-1667, 2007. https://doi.org/10.1590/S1413$\underline{70542007000600009}$.

SOUZA, J.A.; BUZETTI, S.; TEIXEIRA FILHO, M.C.M.; ANDREOTTI, M.; SÁ, M.E.; ORIVALDO, A.R.F. Adubação nitrogenada na cultura do milho safrinha irrigado em plantio direto. Bragantia, v.70, p.447-454,

2011.

https://doi.org/10.1590/S0006$\underline{87052011000200028}$

SOUZA, S.A.; NAKAGAWA, J.; MACHADO, C.G. Teste de envelhecimento acelerado em sementes de aveia preta. Revista Brasileira de Sementes, v.31, n.2, p.155-163, 2009. https://doi.org/10.1590/S010131222009000200018

TEIXEIRA FILHO, M.C.M; BUZETTI, S.; ANDREOTTI, M.; ORIVALDO, A.R.F.; BENETT, C. G. S. Doses, fontes e épocas de aplicação de nitrogênio em trigo irrigado em plantio direto. Pesquisa Agropecuária Brasileira, v.45, n.8, p.797-804, $2010 . \quad$ https://doi.org/10.1590/S0100204X2010000800004

THEAGO, E.Q; BUZETTI, S.; TEIXEIRA FILHO, M.C.M; ANDREOTTI, M.; MEGDA, M.M.; BENETT, C.G.S. Doses, fontes e épocas de aplicação de nitrogênio influenciando teores de clorofila e produtividade do trigo. Revista Brasileira de ciência do Solo, v.38, p.1826- 1835, 2014. 
https://doi.org/10.1590/S0100-

$\underline{06832014000600017 .}$.

VIANA, M.C.M.; FREIRE, F.M.; FERREIRA, J.J.;

MACÊDO, G.A.R.; CANTARUTTI, R.B.;

MASCARENHAS, M.H.T. Adubação nitrogenada na

produção e composição química do capim-

braquiária sob pastejo rotacionado. Revista

Brasileira de Zootecnia, v.40, n.7, p.1497-1503,

$2011 . \quad$ https://doi.org/10.1590/S1516-

$\underline{35982011000700014}$

Recebido para publicação em 03/04/2017

Revisado em 20/08/2017

Aceito em 04/09/2017 